\title{
IgG4-related Disease: the Role of the Surgeon through a Report of a Case
}

\author{
EI Mantonakis, DN Moris, DF Diamantis, AM Pazaiti, AE Papalampros
}

\begin{abstract}
We present a patient with the symptomatic pancreatic disease. Extensive preoperative workup could not reveal the diagnosis beyond doubt, so Whipple's resection was performed, in order to exclude pancreatic adenocarcinoma. Since the difference in diagnosis between autoimmune pancreatitis and pancreatic cancer cannot be made based only on clinical findings, serological and imaging examinations and biopsy are not always feasible, many patients have to undergo surgery. Autoimmune pancreatitis (AIP) is the most common manifestation of a newly recognized entity, IgG4-related systemic disease, affecting many organs and sites. The second most common manifestation, which this patient presented with is salivary gland enlargement, also known as Kuttner's tumour, and it has histopathologic findings in common with autoimmune pancreatitis. The IgG4-related systemic disease can be effectively treated with steroids, so accurate diagnosis, even if is sometimes difficult, can help prevent unnecessary surgery. On the other hand, despite the fact that this entity is not primarily managed by surgery, surgery is often employed for a diagnostic and management purposes.
\end{abstract}

Keywords: Autoimmune, criteria, Kuttner's tumour, pancreatitis, surgery

\section{Enfermedades Relacionadas con la IgG4: el Papel del Cirujano a Través de un Reporte de Caso \\ EI Mantonakis, DN Moris, DF Diamantis, AM Pazaiti, AE Papalampros}

\begin{abstract}
RESUMEN
Presentamos un paciente con la enfermedad pancreática sintomática. El extenso estudio preoperatorio no alcanzó a revelar el diagnóstico con certeza, por lo que se realizó una resección de Whipple, para excluir la posibilidad de un adenocarcinoma de páncreas. Puesto que el diagnóstico diferencial entre la pancreatitis autoinmune y el cáncer de páncreas no se basa sólo en hallazgos clínicos, serológicos, y exámenes por imágenes, y la biopsia no es siempre factible, muchos pacientes tienen que someterse a cirugía. La pancreatitis autoinmune (PAI) es la manifestación más común de una entidad recientemente reconocida: la enfermedad sistémica relacionada con IgG4, que afecta a muchos órganos y sitios. La segunda manifestación, que el paciente también presentó con el agrandamiento de la glándula salival, es conocida como tumor de Kuttner y tiene resultados histopatológicos comunes con la pancreatitis autoinmune. La enfermedad sistémica relacionada con IgG4 puede tratarse eficazmente con esteroides, por lo que un diagnóstico preciso, incluso si a veces es difícil, puede ayudar a prevenir una cirugía innecesaria. Por otro lado, a pesar del hecho de que esta entidad no es principalmente tratada mediante cirugía, la cirugía se emplea a menudo con fines de diagnóstico y manejo.
\end{abstract}

Palabras claves: Autoinmune, criterios, tumor de Kuttner, pancreatitis, cirugía

West Indian Med J 2017; 66 (1): 173

From: First Department of Surgery, Laiko General Hospital, National and Kapodistrian University of Athens, Athens, Greece.

Correspondence: Dr EI Mantonakis, Kehagia 10 Street, Filothei 15237, Greece. Email: lefman@gmail.com

\section{INTRODUCTION}

Whipple's resection is an effective procedure used for the treatment of malignancies of the pancreas. Pancreatic adenocarcinoma, the fifth leading cause of cancer-related mortality, is usually located in the head of the pancreas. Whipple's proce- 
dure is also used, along with other operations, for patients with symptomatic chronic pancreatitis, especially when severe abdominal pain, obstructive jaundice and weight loss are present. Imaging studies cannot always distinguish between a benign mass of the pancreas and neoplasia, and subtotal pancreaticoduodenectomy is considered justifiable, not only for the treatment but sometimes for achieving an accurate diagnosis in patients with clinical suspicions of malignancy (1-4). There is a wide spectrum of inflammatory conditions of the pancreas that resemble, clinically and radiologically, malignancy, which is under-diagnosed and are reported as chronic pancreatitis. These conditions are clinically and histopathologically distinctive forms of chronic pancreatitis that include as follows: chronic toxic and metabolic causes as alcohol abuse, tobacco smoking, gallstone-associated pancreatitis, autoimmune pancreatitis and idiopathic chronic pancreatitis (5).

Autoimmune pancreatitis (AIP) is a recently described entity that is a histologically distinctive form of chronic pancreatitis which belongs to the newly recognized concept of IgG4 related systemic disease. Autoimmune pancreatitis is nowadays classified into two types: Type 1, in which the pancreas is involved in one part of a systemic IgG4 (+) disease and Type 2, which is characterized by histologically confirmed idiopathic duct-centric pancreatitis often with granulocytic lesions, but without IgG4 (+) cells and without systemic involvement (6). Type 1 disease affects other organs and the second most commonly affected site is the salivary glands. Affected organs share common histopathologic findings, including increased infiltration with IgG4 $(+)$ plasma cells and response to therapy with corticosteroids.

\section{CASE REPORT}

In this case report, a 65 -year-old female presented to our clinic with abdominal pain and obstructive jaundice. Abdominal pain appeared two months before presentation when laboratory examinations showed hyperbilirubinaemia, mainly conjugated bilirubin and abnormal liver function tests. Ultrasound of the liver, biliary tract and pancreas showed moderate dilation of the intrahepatic biliary tree, without gallstones and abnormal parenchymal imaging of the pancreas, especially the head. Computed tomography (CT) of the abdomen revealed hepatomegaly with a fatty infiltration, dilated gallbladder, biliary tract without dilation and pancreas with increased size without obvious focal parenchymal lesions. At the time of her admission to the hospital her bilirubin was $5.4 \mathrm{mg} / \mathrm{dL}$ (normal range $0.3-1.2 \mathrm{mg} / \mathrm{dL}$ ), conjugated bilirubin $4.14 \mathrm{mg} / \mathrm{dL}$ (normal range $0-0.3 \mathrm{mg} / \mathrm{dL}$ ), aspartate aminotransferase $310 \mathrm{U} / \mathrm{L}$ (normal range 5-40 U/L), alanine aminotransferase $534 \mathrm{U} / \mathrm{L}$ (normal range 5-40 U/L), gamma-glutamyltransferase 537 $\mathrm{U} / \mathrm{L}$ (normal range 7-32 U/L), alkaline phosphatase $1040 \mathrm{U} / \mathrm{L}$ (normal range 64-280 U/L). The level of CA-19.9 was at borderline values, while IgG4 levels were $121 \mathrm{mg} / \mathrm{dL}$ (normal values $<135 \mathrm{mg} / \mathrm{dL}$ ). The patient was referred for MRI-MRCP which revealed a marginally increased size of the pancreas, with no duct dilation and no focal lesions (Figs. 1 and 2).
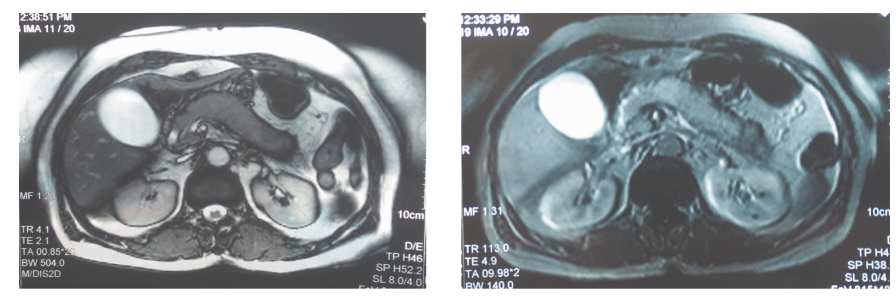

Figs.1, 2: Magnetic resonance imaging sequences of the patient showing a marginally increased size of the pancreas, with no duct dilation and no focal lesions.

The patient underwent endoscopic ultrasound (EUS) with fine needle aspiration (FNA) of the pancreas in an attempt to ensure an accurate diagnosis. Endoscopic ultrasound showed diffuse heterogeneity of the pancreatic parenchyma with fibrosis and a hypoechogenic irregular lesion at the head of the pancreas. It was at that time stated that the EUS findings could not support the diagnosis of chronic pancreatitis, according to recent criteria. Furthermore, cytology test of the FNA reported that the material could not support an accurate diagnosis. An endoscopic retrograde cholangiopancreatography (ERCP) was then conducted which revealed dilation of the initial segment of the pancreatic duct and dilation of the common bile duct. A biliary sphincterotomy was performed and a plastic stent was placed. Since imaging studies and FNA could not make a diagnosis beyond doubt, the patient underwent pancreaticoduodenectomy for presumed pancreatic cancer.

There were no significant complications from the surgery. Pathology report of the pancreas revealed fibrosis and inflammation of the pancreatic parenchyma and destruction of the lobulated architecture. Inflammatory infiltration of the parenchyma by lymphocytes, plasma cells and some eosinophils was identified, along with lymphoid aggregates. Fibrosis and inflammatory infiltration were also identified in the pancreatic ducts and the intra and extrapancreatic bile duct portion, accompanied by obliterative phlebitis. Gallbladder was also affected with inflammatory cells, mainly eosinophils. These findings were compatible with chronic pancreatitis with features indicative of autoimmune pancreatitis. The patient was discharged from hospital on oral steroids for seven months. The patient reported improvement of her symptoms.

Almost two years later, the patient presented with unilateral, painless, firm swelling of the submandibular gland. We decided to remove the gland in order to obtain a definite pathology report, something that was in accordance with our patient's wishes; the pathology report was indicative of "Kuttner's tumour". The gland was infiltrated with inflammatory cells, mainly plasma cells, lymphocytes and eosinophils, as well as with lymphoid aggregates without destruction of glandular lobules. Fibrosis was present and so was obliterative phlebitis. These were indicative of chronic, sclerosing sialadenitis (Kuttner's tumour). IgG4 levels were measured and they were found elevated, $599 \mathrm{mg} / \mathrm{dL}$ (normal values $<135 \mathrm{mg} / \mathrm{dL}$ ). The patient did not report swelling of any other 
gland. For the moment, she does not receive any other treatment.

\section{DISCUSSION}

Autoimmune pancreatitis (AIP) is a rare form of chronic pancreatitis. It was first described in 1961 (7), and in 1995 Yoshida et al (8), proposed the term "autoimmune pancreatitis". Autoimmune pancreatitis is most commonly seen in middle-aged and elderly men with the a mean age of 59 to 68 years. Autoimmune pancreatitis comprises $2 \%-11 \%$ of all cases of chronic pancreatitis (9). It accounts for almost $30 \%$ of patients with benign pancreatic disease or undergoing pancreaticoduodenectomy for presumed pancreatic cancer $(10,11)$. Usually, patients present with enlargement of the pancreas and/or pancreatic mass, with or without painless obstructive jaundice.

In spite of major advances in radiology, in many cases, it is difficult to distinguish pancreatic adenocarcinoma from benign conditions in pancreatic imaging (1-4). Our patient presented with pancreatic enlargement and obstructive jaundice, and, although she had undergone a broad spectrum of radiologic examination, we were unable to establish an indisputable, according to the standing criteria, diagnosis, in order to avoid surgery. Furthermore, a hypoechogenic lesion was found at the head of the pancreas, raising concerns of pancreatic cancer.

For the diagnosis of AIP, the HISORt criteria have been established by Chari and colleagues (12). These criteria include histologic features, characteristic imaging on CT, MRI, ERCP, elevated serum IgG4 levels, other organ involvement and response of a pancreatic/extrapancreatic lesion to steroid therapy (Table 1).

Table 1: Diagnostic criteria for autoimmune pancreatitis (The HISORt Criteria): Definitions

\begin{tabular}{|c|c|}
\hline Category & Criteria \\
\hline \multirow[t]{2}{*}{ Histology } & $\begin{array}{l}\text { At least one of the following: } \\
\text { (1) Periductal lymphoplasmacytic infiltrate with } \\
\text { obliterative phlebitis and storiform fibrosis } \\
\text { (LPSP) }\end{array}$ \\
\hline & $\begin{array}{l}\text { (2) Lymphoplasmacytic infiltrate with storiform } \\
\text { fibrosis showing abundant ( } 10 \text { cells/HPF) IgG4- } \\
\text { positive cells }\end{array}$ \\
\hline Pancreatic imaging & $\begin{array}{l}\text { Typical: diffusely enlarged gland with delayed } \\
\text { (rim) enhancement; diffusely irregular, attenu- } \\
\text { ated main pancreatic duct } \\
\text { Others: Focal pancreatic mass/enlargement; } \\
\text { focal pancreatic duct stricture; pancreatic atro- } \\
\text { phy; pancreatic calcification; or pancreatitis }\end{array}$ \\
\hline Serology & $\begin{array}{l}\text { Elevated serum IgG4 level (normal, 8-140 } \\
\mathrm{mg} / \mathrm{dL} \text { ) }\end{array}$ \\
\hline Other organ involvement & $\begin{array}{l}\text { Hilar/intrahepatic biliary strictures, persistent } \\
\text { distal biliary stricture, parotid/lacrimal gland in- } \\
\text { volvement, mediastinal lymphadenopathy, } \\
\text { retroperitoneal fibrosis }\end{array}$ \\
\hline Response to steroid therapy & $\begin{array}{l}\text { Resolution/marked improvement of pancreatic/ } \\
\text { extrapancreatic manifestation with steroid ther- } \\
\text { apy }\end{array}$ \\
\hline
\end{tabular}

A diagnosis of autoimmune pancreatitis is when one of the following are fulfilled: histology or imaging and serum or strong clinical suspicion of autoimmune pancreatitis (idiopathic pancreatic disease and elevated serum levels of IgG4 and/or other organ involvement) and response to steroid therapy. The Japanese Pancreas society has also suggested and in 2006 revised its criteria (13), which include radiologic imaging showing diffuse or segmental narrowing of the main pancreatic duct with irregular walls and diffuse or localized enlargement of the pancreas, high IgG4 values or presence of autoantibodies and histological evidence of lymphoplasmatic infiltration and fibrosis. A positive diagnosis is considered when all three criteria are met or when criterion one is combined with either two or three.

Histology is usually highly suggestive of the disease (4). Type 1 disease is characterized by lymphoplasmacytic sclerosing pancreatitis or more than $10 \mathrm{IgG} 4(+)$ cells with at least two of the following: periductal lymphoplasmacytic infiltrate, obliterative phlebitis and acinar fibrosis. Type 2 disease shows idiopathic duct-centric pancreatitis or a granulocytic epithelial lesion in the pancreatic duct with minimal IgG4 $(+)$ cells in the pancreatic parenchyma (4).

Elevated IgG4 serum levels more than twice the normal values $(>280 \mathrm{mg} / \mathrm{dL})$ can be highly suggestive of AIP, but without excluding the possibility of pancreatic cancer (4). Elevated but lower values $(140-280 \mathrm{mg} / \mathrm{dL}$ ) can be suggestive of AIP, but can also be found in a large percentage of patients with pancreatic cancer $(10 \%)$, healthy subjects $(5 \%)$ or other diseases (14-18). It has been noted that serum IgG4 concentration tends to increase the number of organs involved and usually decreases after treatment glucocorticoids.

As noted earlier, modern classification distinguishes two Types of AIP [Type 1, and Type 2] (6). Type 1 AIP is usually associated with other autoimmune diseases, such as Sjogren syndrome, salivary gland disease, retroperitoneal fibrosis, and inflammatory bowel disease. Histopathologic, immunohistochemical, serologic findings in patients and also the response of autoimmune pancreatitis to corticosteroid therapy, suggest that there is an autoimmune mechanism for the onset of this disease. The IgG4-related disease is a rare lymphoproliferative disorder associated with inflammation resulting in fibrotic and sclerotic changes in affected organs. Pancreas, salivary and lacrimal glands are mainly affected, but other organs as well can be involved, such as the biliary tract, the liver, the gallbladder, other parts of the gastrointestinal tract, kidneys, retroperitoneum and mesentery, thyroid, breast, lungs, aorta, orbit, mediastinum, pituitary gland, prostate and lymph nodes. IgG4 is characterized by elevated IgG4 levels, infiltration with IgG4 plasma cells, and sclerosis of the affected organ. Inflammation of the affected organ can result in the destruction of the parenchyma, but usually, it responds to corticosteroid therapy.

Chronic sclerosing sialadenitis, also known as Kuttner's tumour, belongs to the spectrum of IgG4-related diseases (19). Salivary glands are the second most affected site in IgG4 re- 
lated disease. The submandibular gland is most commonly affected than any other salivary gland, although the parotid gland can also be involved (20). Chronic sclerosing sialadenitis typically affects middle-aged to elderly patients and presents as a bilateral or unilateral enlargement of the salivary gland. Chronic sclerosing sialadenitis cannot easily be distinguished from neoplasia. Histologically, infiltration of the salivary gland with lymphocytes and plasma cells and fibrosis, results in the destruction of the lobular architecture of the gland, while obliterative phlebitis can also be present. Mikulicz disease is an idiopathic, painless, and symmetric, bilateral enlargement of the lacrimal, salivary, both parotid and submandibular glands. Sjögren syndrome can also affect the salivary glands and can co-exist with autoimmune pancreatitis.

Corticosteroids are the first choice for treating autoimmune pancreatitis and extrapancreatic manifestations of IgG4related systemic disease, as there is a significant response to steroid therapy. Standard dose and schedule have not yet been established. Before initiating treatment, obstructive jaundice should be managed, usually, by endoscopic bile-duct stenting, and also blood glucose levels should be controlled in patients with diabetes mellitus. Initially, oral prednisolone is administered at a dose of $0.6 \mathrm{mg} / \mathrm{kg}$ per day for two to four weeks. Then the dose is tapered by $5 \mathrm{mg}$ every one to two weeks, requiring a period of three to six months. Evaluation of response to steroid therapy should take place two weeks after initiation of treatment, and a poor response to treatment would increase the possibility of pancreatic cancer rather than autoimmune pancreatitis. Due to the increased possibility of relapse, maintenance therapy is recommended to all patients, for a maximum of three years. In patients that relapse during or after treatment, re-administration or increase of the dose can be effective.

Since there is an effective treatment for autoimmune pancreatitis and the extrapancreatic manifestations of IgG4-related disease, accurate diagnosis is necessary. But distinguishing autoimmune pancreatitis from malignancy is not always feasible, based on clinical manifestations, imaging and serum results, so laparotomy or pancreatic resection cannot be always avoided $(21,22)$. Since pancreatic surgery involves major operations, it should be noted that especially these patients with a possible benign disease should be referred to a specialized centre, where it is proven that morbidity and mortality are lower. Some of the reasons mentioned in the literature for unnecessary operations are a high threshold for an initiating an IgG4 evaluation, false-positive cytologic evaluations for malignancy, and failure to recognize non-classic initial presentations or recurrence of disease (23). Imaging is a crucial component of the diagnostic process and specific strategies should be formed for the diagnosis and treatment of the disease.

\section{CONCLUSION}

Surgeons must first be aware of this newly recognized entity and its entire spectrum of manifestations. Since steroids ap- pear to be the cornerstone of treatment, accurate diagnosis, even if is sometimes difficult, can help prevent unnecessary surgery. In cases of a doubt though, surgery can and should be used for diagnosis and treatment.

\section{REFERENCES}

1. Sahani DV, Kalva SP, Farrell J, Maher MM, Saini S, Mueller PR et al. Autoimmune pancreatitis: imaging features. Radio 2004; 233: 345-52.

2. Kamisawa T, Egawa N, Nakajima H, Tsuruta K, Okamoto A, Kamata $\mathrm{N}$. Clinical difficulties in the differentiation of autoimmune pancreatitis and pancreatic carcinoma. The Amer J Gastro 2003; 98: 2694-9.

3. Nakazawa T, Ohara H, Sano H, Ando T, Imai H, Takada H et al. Difficulty in diagnosing autoimmune pancreatitis by imaging findings. Gastro endoscopy 2007; 65: 99-108.

4. Chari ST, Takahashi N, Levy MJ, Smyrk TC, Clain JE, Pearson RK et al. A diagnostic strategy to distinguish autoimmune pancreatitis from pancreatic cancer. Clin Gastroenterol and Hepatol 2009; 7: 1097-103.

5. Etemad B, Whitcomb DC. Chronic pancreatitis: diagnosis, classification, and new genetic developments. Gastro 2001; 120: 682-707.

6. Sah RP, Chari ST, Pannala R, Sugumar A, Clain JE, Levy MJ et al. Differences in clinical profile and relapse rate of Type 1 versus Type 2 autoimmune pancreatitis. Gastroenterology 2010; 139: 140-8; quiz e12-3.

7. Sarles H, Sarles JC, Muratore R, Guien C. Chronic inflammatory sclerosis of the pancreas - an autonomous pancreatic disease? Am J Dig Dis 1961; 6: 688-98.

8. Yoshida K, Toki F, Takeuchi T, Watanabe S, Shiratori K, Hayashi N.Chronic pancreatitis caused by an autoimmune abnormality. Proposal of the concept of autoimmune pancreatitis. Digestive diseases and sciences 1995; 40: 1561-8.

9. Chari ST. Diagnosis of autoimmune pancreatitis using its five cardinal features: introducing the Mayo Clinic's HISORt criteria. J Gastro 2007; 42(Suppl 18): 39-41.

10. Hardacre JM, Iacobuzio-Donahue CA, Sohn TA, Abraham SC, Yeo CJ, Lillemoe KD et al. Results of pancreaticoduodenectomy for lymphoplasmacytic sclerosing pancreatitis. Annals Surg 2003; 237: 853-8.

11. Abraham SC, Wilentz RE, Yeo CJ, Sohn TA, Cameron JL, Boitnott JK et al. Pancreaticoduodenectomy (Whipple resections) in patients without malignancy: are they all 'chronic pancreatitis'? Am J Surg Pathol 2003; 27: $110-20$.

12. Chari ST, Smyrk TC, Levy MJ, Topazian MD, Takahashi N, Zhang L et al. Diagnosis of autoimmune pancreatitis: the Mayo Clinic experience. Clin Gastroenterol Hepatology 2006; 4: 1010-6.

13. Okazaki K, Kawa S, Kamisawa T, Naruse S, Tanaka S, Nishimori I et al. Clinical diagnostic criteria of autoimmune pancreatitis: revised proposal J Gastroenterol 2006; 41: 626-31.

14. Hamano H, Kawa S, Horiuchi A, Unno H, Furuya N, Akamatsu T et al. High serum IgG4 concentrations in patients with sclerosing pancreatitis The New Engl J M ed 2001; 344: 732-38.

15. Raina A, Krasinskas AM, Greer JB, Lamb J, Fink E, Moser AJ et al. Serum immunoglobulin G fraction 4 levels in pancreatic cancer: elevations not associated with autoimmune pancreatitis. Arch Pathol Lab Med 2008; 132: 48-53.

16. Ghazale A, Chari ST, Smyrk TC, Levy MJ, Topazian MD, Takahashi N et al. Value of serum IgG4 in the diagnosis of autoimmune pancreatitis and in distinguishing it from pancreatic cancer. Am J Gastroenterol 2007; 102: 1646-53.

17. Sugumar A, Kloppel G, Chari ST. Autoimmune pancreatitis: pathologic subtypes and their implications for its diagnosis. Am J Gastroenterol 2009; 104: 2308-10.

18. Sah RP, Chari ST. Serologic issues in IgG4-related systemic disease and autoimmune pancreatitis. Curr Opin Rheumatol 2011; 23: 108-13.

19. Geyer JT, Ferry JA, Harris NL, Stone JH, Zukerberg LR, Lauwers GY, et al. Chronic sclerosing sialadenitis (Kuttner tumor) is an IgG4-associated disease. Am J Surg Pathol 2010; 34: 202-10. 
20. Williams HK, Connor R, Edmondson H. Chronic sclerosing sialadenitis of the submandibular and parotid glands: a report of a case and review of the literature. Oral Surg Oral Med Oral Pathol Oral Radiol Endod 2000; 89: 720-3.

21. Takuma K, Kamisawa T, Gopalakrishna R, Hara S, Tabata T, Inaba Y et al. Strategy to differentiate autoimmune pancreatitis from pancreas cancer. World J Gastroenterol 2012; 18: 1015-20.
22. Kamisawa T, Okamoto A. IgG4-related sclerosing disease. World J Gastroenterol 2008; 14: 3948-55.

23. Learn PA, Grossman EB, Do RK, Allen PJ, Brennan MF, D’Angelica MI et al. Pitfalls in avoiding operation for autoimmune pancreatitis. Surg 2011; 150: 968-74. 